\title{
Exploring the Meaning of Childhood Disability: Perceptions of Disability among Mothers of Children with Disabilities (CWD) in Kuwait
}

Sudha R. Raman, PT, Department of Epidemiology, Gillings School of Global Public Health, University of North Carolina at Chapel Hill, Chapel Hill, North Carolina, USA

Shilpa Mandoda, MSc, Research Associate, Department of Physical Therapy, University of Toronto, Toronto, Ontario, Canada

Laila Kasim Hussain, PT, Physiotherapist, Department of Paediatric Physiotherapy, Physical Medicine and Rehabilitation Hospital, Kuwait

Niamh Foley, PT, Physiotherapist, Fawzia Sultan Rehabilitation Institute, Kuwait

Elham Hamdan, MD, Medical Director, Fawzia Sultan Rehabilitation Institute, Kuwait

Michel Landry, PT, PhD, Assistant Professor, Department of Physical Therapy, University of Toronto, Toronto, Ontario, Canada, Fawzia Sultan Rehabilitation Institute, Kuwait

Correspondence may be directed to: Michel D. Landry, Department of Physical Therapy, University of Toronto, 160-500, University Avenue, Toronto, Ontario, Canada, M5G 1V7, Fax: 416-946-8562, Email: mike.landry@utoronto.ca

\footnotetext{
Abstract

The purpose of this exploratory research was to examine perceptions of mothers with children with disabilities (CWD) in Kuwait in order to understand the meaning of disability from their perspective and to explore the extent to which such perceptions influence rehabilitative services that their children receive. Ten semi-structured interviews were conducted with mothers of CWD receiving services at a large pediatric facility in Kuwait. Four themes emerged from the interviews: (1) mother's perceptions of disability, (2) mother's extended caregiver role, (3) religious beliefs as a coping strategy, and (4) perception of rehabilitation services. Our findings suggest that despite a traditional acceptance
} 
of disability as divine intervention or a challenge sent to them by God, mothers were motivated to maximize rehabilitation services in order to improve the functional capacity of their children. Kuwaiti mothers may hold both the fatalistic view of disability, and the belief that the course of disability can be altered through a rehabilitative intervention, in tension. An appreciation of this phenomenon might move toward a rehabilitation delivery model that integrates and harmonizes such beliefs.

\section{Background}

The World Health Organization (WHO) estimates that $10 \%$ of the global population experiences some form of disability, including approximately 200 million children (2008). In the not-so-distant past, disability was understood to be the relative inability to perform or accomplish tasks that one's peers could perform. Terms such as invalid were grounded in this pejorative and depreciatory understanding (Brown et al. 2000; Gething 1992; Miller 1996). Over time, however, the conceptualization of disability has evolved. Generally, people with disabilities are now considered to have varying degrees of ability measured along a multidimensional continuum (Masala and Petretto 2008; Wahl et al. 2009; Wiart and Darrah 2002;). At one end of the continuum, a person may have no physical, mental or emotional limitations, while at the other end, physical, mental or emotional factors can create important limitations in performance. The International Classification of Functioning, Disability and Health (ICF) defines disability as an umbrella term that characterizes all impairments, activity limitations and participation restrictions relating to the body, the individual and society (WHO 1980, 2001). Although there are academic debates regarding the ICF model (Cieza et al. 2009; Rauch et al. 2009; Wynia et al. 2009), it is likely that parents of children with disabilities perceive, define and contextualize disability in multiple ways. Beyond academic definitions, the importance of understanding parents' perceptions of disability is critical in order to optimize the delivery of health services within global, regional and local health and social care communities (Armstrong and Ager 2005; Gan et al. 2008; Law et al. 2003). This understanding may in turn contribute to functional improvements for the individual and, by extension, further the actualization of human rights in all persons with disabilities.

It has been suggested that perception of disability may be a pivotal determinant of the health services sought by mothers of children with disabilities (Danesco 1997; Diken 2006). In other words, both biomedical and traditional perceptions, attitudes and beliefs about disability may influence a mother's care-seeking behaviour. For instance, a Turkish study by Diken (2006) reported that mothers who perceived their child's disability as the result of a traditional cause were more likely to seek a traditional intervention, whereas mothers who perceived a biomedical cause were more likely to pursue formal medical services. Furthermore, it has also been reported that individuals from many cultures hold biomedical and traditional beliefs simultaneously regarding the nature and causation of disability. This may lead them to pursue multiple concurrent treatments (Danesco 1997; Diken 2006; Hosain et al. 2005).

Mothers' perceptions of disability may also be profoundly influenced by attitudes of their family and community. In a case study from the United States, researchers reported that mothers were more likely to feel embarrassed and guilty about their child's disability if they themselves felt that people with disabilities were devalued and discriminated against in their community (Green 2003). Additionally, the same research group found that mothers who experienced a great deal of stigma related to their child's disability reported a higher burden of care for their child, were much less likely to interact with peers and were less likely to investigate age-matched interactions for their children (Green 2003). Members of the current team of investigators have been involved in exploring the perception of disability among mothers who have a child with a disability (CWD) in different countries in order to explore the links between perception of disability and health-seeking behaviours. For instance, in a study by Maloni et al. (2010), the authors concluded that understanding mothers' perceptions of disability and treatment, and the myriad of factors that influence those perceptions, provides valuable knowledge to assist in planning and delivering family-centred rehabilitation services for CWD. In a follow-up study, Daudji et al. (in press) expanded the research agenda 
by investigating perceptions among recent South Asian immigrants to Canada and concluded that in this population, mothers' perceptions of their child's disability were influenced both by traditional cultural notions of disability and by those imposed on them through institutional and societal norms within their new country. To help these mothers achieve a positive and realistic frame of reference for their child's disability, Daudji et al. suggested that healthcare providers should play an important role in advocating for access to social supports and helping mothers set achievable goals for their child. Rehabilitation has a central role in helping mothers understand the nature of their child's disability and how to manage it. Ultimately, an understanding of parental perception is thought to improve the long-term social and educational opportunities for CWD.

The purpose of this current study was to expand upon previous research and examine mothers' perceptions of CWD in Kuwait in order to understand the meaning of their perception of disability and to explore the extent to which such perceptions influence the rehabilitative services their children receive. In this study, Kuwait serves as a unique example of a society with a strong familial and religious-based organization that has also recently experienced rapid development and change from the tremendous wealth generated from the petroleum industry.

\section{Methods}

A descriptive qualitative design was employed to address the research objective. Approval for the study was obtained through the Kuwaiti hospital's senior management and the research ethics process where the study took place.

\section{Identification and Recruitment of Participants}

We used convenience sampling to identify participants. They were included if they were (1) a mother of a child with a disability attending rehabilitation at a large pediatric facility in Kuwait City, and (2) able and willing to participate in a 30-minute face-to-face interview in June or July 2009. A hospital staff member not involved in patient care recruited mothers who met the inclusion criteria. Potential participants were told about the study objective, informed that their participation was completely voluntary, that all information would remain confidential, and that they would be free to withdraw at any time without consequence. They were also assured that choosing not to participate would in no way affect their child's treatment. If the mother was interested in participating, the staff member scheduled an interview session with the research team. If she remained interested after this first information session with the research assistant, an interview was scheduled at a convenient time. The potential risk of discomfort at disclosing personal information regarding mothers' experiences with a CWD was discussed during the first contact with the research assistant and again at the time of the informed consent process that preceded each interview.

Primary data was collected through semi-structured face-to-face interviews. The interview schedule consisted of 21 structured open- and close-ended questions. Trained research assistants conducted all 10 key informant interviews at the facility between June and July 2009. All interviews were conducted in Arabic, and once the interview was completed, the research assistant immediately transcribed it into an MS Word document. Each interview was then translated into English by the same research assistant. A second research assistant who had not transcribed the interviews reviewed each of the audio recordings and subsequent transcriptions in order to ensure that the qualitative data was accurately transcribed and translated.

\section{Data Analysis}

Transcribed interview data were entered into a qualitative data analysis software package (NVivo 2.0) for systematic coding. The research team then performed content analysis to identify themes that emerged from the interviews. Content analysis, or qualitative description, has been reported as useful when the description of phenomena is desired (Pope et al. 2000). The identified themes were based on informants' collective perceptions and experiences relevant to the issues being explored in the study. Once transcripts had been coded, reports were generated so that the research team 
could analyze the data according to the research objectives. The team met regularly from August to October 2009 to share impressions, develop main themes and discuss alternate interpretations.

\section{Results}

A total of 10 mothers consented to participate in the study (Table 1). Their ages ranged from 28 to 38 years. Three were not familiar with the medical term for their child's disability, whereas the others reported that their child was diagnosed with one the following: cerebral palsy $(n=3)$, congenital defect of the pelvis $(n=1)$, hemiplegia $(n=1)$, quadruple paralysis $(n=1)$ and stroke $(n=1)$.

Four themes emerged from the data: (1) mother's perceptions of disability, (2) mother's extended caregiver role, (3) religious beliefs as a coping strategy, and (4) perception of rehabilitation services.

Table 1. Participant demographics

\begin{tabular}{|l|c|c|c|c|}
\hline $\begin{array}{l}\text { Participant } \\
\text { number }\end{array}$ & $\begin{array}{c}\text { Age of mother } \\
\text { (years) }\end{array}$ & $\begin{array}{c}\text { Mother's description of disability } \\
\text { Sex of child }\end{array}$ & $\begin{array}{c}\text { Total number of children } \\
\text { in family }\end{array}$ \\
\hline 2 & 33 & Cerebral palsy & F (and pregnant) \\
\hline 3 & 30 & Congenital defect in pelvis & F & 2 \\
\hline 4 & 35 & Cerebral palsy & M & 5 \\
\hline 5 & 30 & Unidentified & F & 5 \\
\hline 6 & 31 & Hemiplegia & F & 2 \\
\hline 7 & 29 & Cuadruple paralysis & M & 2 \\
\hline 8 & 29 & Unidentified & F & 3 \\
\hline 9 & 28 & Cerebral palsy & F & 2 \\
\hline 10 & & Unidentified & 4 \\
\hline
\end{tabular}

\section{Mother's Perceptions of Disability}

In general, participants felt uncomfortable with the word disabled and believed it portrayed their child negatively. From their perspective, disability was synonymous with having an incomplete child. Despite their discomfort with this term, however, it may be important to note that the mothers continued to use it throughout the interviews. Many felt that even though their child was disadvantaged in some ways, he or she was gifted in others that "normal" people were not. For instance, one mother stated, "...in my opinion a disabled person has achievements and more creativity than normal people do." The belief that CWDs possessed special and unique features that surpassed their non-disabled peers was a perception all participants shared.

Participants also believed that their families and community had preconceived, negative perceptions about individuals with disabilities. The mothers reported that words such as pity and sympathy were often used to describe the general community's perception of their CWD. They felt that although their child had many abilities, their families and communities perceived that he or she was fully incapable and needed constant help. One participant noted how members of the community were more sympathetic toward her child once they were aware of her disability, but she feared that 
that this "over sympathy" would further segregate her CWD from other children in the community. According to this mother,

Sometimes they [society] over-sympathize with them [CWD], which I think affects disabled people and makes them feel that they are not normal. In my community they feel sympathy towards her because she is not capable like other kids.

Participants remarked that the community should not "overly sympathize" with their disabled child or give him or her special treatment. Treating the child as "normal" would help him or her integrate, and feel more integrated, in society. For example, one mother with a child with cerebral palsy asserted that,

We shouldn't sympathize with disabled people, so that they doesn't feel incomplete. I treat her like a normal child, I talk to her even though she hasn't started speaking yet ... I don't want her to get used to special treatment.

Despite the positive perspective on the abilities of CWD, and the suggestion that community members should not demonstrate overt sympathy for them, a minority of participant mothers themselves expressed a deep sense of internal sympathy for their child regarding the challenges that he or she will face in the future. For instance, one mother revealed, "I feel devastated when I see other kids her age playing while she's sitting next to me." These dual perspectives outline a possible dissonance between outward and verbal perspectives on disability and the internal, more intimate perspective about the child.

\section{Mother's Extended Caregiver Role}

Participants reported giving greater attention to their CWD than to their non-disabled children, because they felt the child had greater needs. A large amount of the mothers' time was dedicated to caring for their child, meeting special needs and fulfilling operational tasks such as taking the child to medical and rehabilitation appointments. All participants said they dedicate time on a daily or weekly basis to attend appointments with their child. The following two quotations reflect this perceived extended caregiver role:

When I discovered his disability, I thought that I need to concentrate more on my child and their needs. The normal person can take care of himself but he needs more care from me.

I need to take care of her a lot more than before [she was disabled]; when she had appointments I didn't go, but now I must take her to all her appointments.

Participants expressed a great deal of concern regarding their feelings of exhaustion and stress secondary to their extended caregiver role. They found it difficult to balance their time between professional careers and their traditional role in the family unit, including caring for their children. The perceived inability to fulfil a traditional role within the family due to the extended caregiver role for the CWD had created stress within their family units over the years, and they feared that this would become even more challenging in the future. The following two quotations represent the perspective of increased burden of care associated with the mothers' extended caregiver role.

I'm always busy. Once I finish my work I go home directly and always stay with her, and I don't leave her unless there is something important; otherwise. I'm always with her.

My colleagues at my work don't understand what I'm going through and that I have to leave my work to bring her to here [the rehabilitation centre] and then go back to work again. Having a disabled child is different than having a normal child. 
The mothers' caregiving role was, in general, described as being extensive and appeared to cause feelings of distress in all of them.

\section{Religious Belief as a Coping Strategy}

All participants in the study expressed very strong religious beliefs and held that these beliefs provided a strategy that allowed them to cope with their personal perspective on disability and their extended caregiving role. All mothers reported that it was "fate" or "divine intervention" that God, or Allah, chose them to care for a CWD. They believed that their CWD was given to them for a particular reason. For instance,

Some people when they know that their child is disabled, they say "why did Allah let this happen?" But I thought that Allah did this for a reason, and he did this because he loves me.

It was common for participants to perceive that their child's disability was the will of God, and they expressed gratitude toward him numerous times during the interview. For instance, one participant stated, "If Allah wants her to be like this permanently, then I can't do anything to change it. Thanks to him anyway." For all participants, grounding the explanation of disability from a fatalistic perspective appeared to provide a context for interpreting and coping with the internal and external issues that surround the CWD. Even those who specifically described their CWD's medical diagnosis held this view.

In additional to this traditional view of disability, a minority of participants also perceived that their child's disability was given to them as a "test from him [Allah], to see how patient I am." One recited a prayer from the Quraan during the interview, which translates to, "Thanks to Allah, who is the only one that we thank when something wrong happens." This subgroup of three participants believed that having a CWD was as a challenge or test sent by God, and that if they could overcome this challenge, it would strengthen their faith. For instance,

I ask Allah to make him better a lot and sometimes when I feel that there is no hope my faith helps me not give up ... thanks to Allah I feel that my faith has increased, now I'm stronger than before.

Based on these perspectives, although all participants shared a fatalistic perspective on their child's disability, a minority appear to describe their circumstances as a challenge, or mission. They believe that they must overcome this challenge and in doing so their faith will be strengthened by God. Although our qualitative data do not allow us to establish an empirical link, it was suggested that the group who perceived the disability as a challenge sent by God may be more motivated to alter the course of the disability through rehabilitation.

Despite the underlying perceptions, a strong religious faith among both groups kept participants hopeful about their child's progress and future potential. As will be more fully described in the next section, all mothers expressed tremendous willingness to focus on altering the course of their child's disability through rehabilitation services.

\section{Perception of Rehabilitation Services}

Overall, participants found that rehabilitation services had improved their CWD's condition. They described the level of care from the centre where they were receiving rehabilitation services as "excellent" and that staff were very helpful; some reported being surprised at how friendly and knowledgeable the staff were toward them. Although there was no expectation of a cure for the disability, all participants were pleased to have their child involved in rehabilitation as a way of providing improvement in their function.

Despite the overall positive experience with rehabilitation, participants reported a series of barriers, categorized into two main areas: (1) a shortage of rehabilitation staff, and (2) difficulty 
with follow through of prescribed home-based therapeutic regimes. Although we discuss these two items separately below, they appear to be linked in many ways.

First, participants felt that the facility had long wait times and was becoming overcrowded, thus limiting the length of scheduled appointment times. Staff shortages were also observed and, while rehabilitation resulted in improvements to their child's physical abilities, participants felt that a greater number of appointments would yield better results. They wanted more frequent and intense rehabilitation, and perceived that there was a causal link between disability and frequency of treatment. In other words, for them, more rehabilitation translated in improved function and minimization of disability. For example, according to one mother,

The centre is excellent and the staff is very nice.... I want him to be better, there [are] a lot of patients who wait for three or four months to get the treatment started. I'm waiting for an occupational therapist to call to me to set up an appointment. They need more staff.

Another participant reflected a similar perspective when she reported,

[Therapy] is really useful, but the problem is that there are not enough appointments; for example, she only gets eight sessions in hydrotherapy; then it stops. She just had a surgery and they gave her eight sessions of hydrotherapy and 1.5 to 2 months of physical therapy. After that they gave her a break because they have a lot of patients and they are under-staffed, not enough of them to take care of all the patients.

Second, participants expressed difficulty in carrying out the prescribed rehabilitation exercises and also reported that this process was made worse due to lack of co-operation from their children. Participants described scenarios where the rehabilitation providers asked them to follow through with home programs with their child, between sessions at the pediatric facility. The mothers described not fully understanding the home program and expressed concern that they would not do the home exercises correctly. Ultimately, they did not necessarily see this as their role and appeared to rely heavily on the rehabilitation provider and the hospital for the delivery of services. The following quotation exemplifies this perspective.

I went to all of her appointments to know if she is getting better or not, and the physical therapist told me that I have to do two hours of exercise with her daily, but it's hard to do the exercises at home ... then they [physical and occupational therapists] told me to do the exercises to her for three months, but it was difficult to do it at home and my daughter didn't respond well with me. Now I applied for her to be treated abroad, even though her case can be treated [here in Kuwait] but I'm afraid that it may get worse.

All mothers expressed the belief that rehabilitation services have, and would, benefit their children. The interpretation is that more rehabilitation services provided at the hospital would yield better outcomes. The role of the mothers, and by extension their families and communities, was minimized along this rehabilitative trajectory. As such, there was concern about the frequency of service delivery and the mothers' ability to provide these services through home-based programs.

\section{Discussion}

Participants perceived that their child was capable of many activities and that their disability was not a limitation to their future potential. We found in this study that mothers were able to see beyond their child's physical limitation to creative strengths that were not present in other children. The community in which they lived, however, did not always recognize these qualities. Although we found no related literature based in Kuwait, research from the United Arab Emirates, a neighbouring country in the Arabian Gulf region, reported that families with disabled children perceive disability 
to be humiliating and shameful (Crabtree 2007). However, Crabtree (2007) suggested that although stigma against people with disabilities remains prevalent in Middle Eastern and Gulf countries, it has in many ways improved over time. Mothers in this study seemed to echo these progressive views by indicating that Kuwaiti society does indeed exert negative influences, but rather than from a foundation of humiliation and shame as suggested by Youssef (1994), the negative influence may be due to being "overly sympathetic" or patronizing to the child and his or her challenges. While perceptions are slow to change, and further investigations are warranted, it appears there may be an ongoing evolution of the perception of disability in Kuwait.

It also appears that the age and gender of a disabled child may have influenced the mother's perception. For instance, Khamis (2007) indicated that levels of stress in parents decreases as the child gets older. At the time of data collection, no information was gathered on the present age of the disabled child; however, interviews indicated that mothers found out about their child's disability at or before birth, or at six months or one year of age.

A majority of the mothers were aware of the medical condition underlying their child's disability, but simultaneously believed that God had chosen them to take on the responsibility of raising a CWD. Most believed that their child was given to them by divine intervention, while a sub-sample also thought that their CWD was sent to them a test or challenge from God. Parents in many cultures have often depicted their children's disability as a result of fate, divine punishment or intervention due to peculiar events, and other religious or socio-cultural beliefs (Danesco 1997). The role of religion and the will of God have been reported in a previous study (Daudji et al. in press), where mothers believed that this path had been chosen for them and that they were given this gift by God because of their personal resources, knowledge and strength, resources that are necessary to be responsible for a child with a disability. Some authors have argued that attributing some responsibility to God also allows a mother cope with the stresses associated with having a CWD (Balasundaram 2007; Burker et al. 2005; Rippentrop et al. 2005; Treloar 2002). Moreover, attributing responsibility to God has been found in previous studies. Chang and McConkey (2008) studied the perceptions of 117 Taiwanese mothers and fathers in Tapei, where the population is predominantly Buddhist. The authors revealed that mothers felt social isolation and encountered social stigma from the community. The mothers felt they could not attend the temple any more because they had been told that the disability was a result of their having sinned. Similar findings were also found Huang et al. (2009), where Taiwanese mothers believed their child was disabled because of his or her bad karma from a previous life. Croot et al (2008) interviewed 16 Pakistani parents and one grandparent in the United Kingdom. Parents attributed their child's disability as a gift or a test from God, or a curse from evil spirits. Others believed they were chosen to have a child with a disability for some divine purpose unknown in this life. Some also thought it was a punishment from God for their wrongdoing.

In this study, we found a strong link between perception of disability and religious beliefs, suggesting that that concept of disability is framed from a spiritual perspective, not according to biomedical frameworks and their components, such as the ICF model.

Sen and Yurtsever (2007) suggested that mothers reported having difficulty in balancing their worklife and caring for a CWD, and Brandon (2007) reported that a mother raising a CWD spent less time on average on personal care and recreation than other mothers. More time was spent socializing, since they found support in the shared experience of other mothers of children with disabilities. It may also be important to note that the same study reported that a father's personal care time per week was not affected as greatly as the mother's, supporting our finding of mothers' extensive responsibility their children. Mothers' responsibilities and associated stresses were mitigated in part by religious beliefs about the value of their situation. Respondents in our study mentioned receiving support from family, friends and the community; this was also reported by Daudji et al. (in press) and Maloni et al. (2010). Mothers did not mention the role of their husbands in caregiving for their child, suggesting that, at least in this convenience sample, mothers had the primary responsibility for caring for their child and ensuring they attended rehabilitation appointments. Although community 
perceptions and reactions to disability were noted as potentially problematic, the overall impression from these mothers was that their community and religious background gave them support and helped them to cope with the responsibility.

This study sought to explore how Kuwaiti mothers of CWD perceive disability and, as such, provides insight regarding the impact that these perceptions may have on the care they seek for their children. Our data now provide an initial framework from which to consider how these views may influence what services Kuwaiti mothers seeks for their children. For instance, we have noted that there may be a different understanding of the role of God (e.g., some believe it is fate; others go further and interpret their CWD as a test or challenge they must overcome) in explaining how and why these mothers had child with a disability. Despite their fatalistic views, however, mothers perceived that rehabilitation services altered the trajectory of disability. On the other hand, despite the positive view of rehabilitation services, it is not clear that the participants accept that they, their families and their communities have a role to play in the rehabilitation process. They expressed concern over the insufficient amount of rehabilitation their child was receiving and articulated that they were unclear on how to follow through with home-based rehabilitation programs. These findings can provide rehabilitation health professionals with insight into the experiences that mothers in Kuwait face. Outside Kuwait, the experiences and cultural beliefs may be useful to health professionals who treat Kuwaitis who have migrated to other parts of the world, as well as populations with strong similar religious beliefs.

\section{Implications for Rehabilitation Delivery}

Irrespective of the ways in which participants conceptualized disability, their view that rehabilitation is valued and capable of making an impact indicates their readiness to access the services. However, the extent to which these mother can, or will, actively participate in their children's rehabilitation remains unclear. What has emerged from this research is that the mothers who participated in this study perceive themselves as having little responsibility in the delivery of services at home. This dichotomy between strongly supporting rehabilitation on one hand, and interpreting a relatively minor role for themselves within the rehabilitation process on the other, may highlight an important gap along the rehabilitative trajectory. Mothers perceive a large and important role as the extended caregiver but do not necessarily interpret rehabilitation as a process that is integrated into activities of daily living. It is generally common practice in pediatric rehabilitation to create home-based programs in order to amplify and sustain the gains made in the application of rehabilitation.

The persistence of this belief should encourage clinicians to focus on addressing the institutional barriers or personal factors that prevent mothers from carrying out their home programs. Kerem Günel (2009) and King et al. (2004) have suggested that adopting a client- and family-centred approach, by including the family in clinical decision-making regarding the rehabilitative process with the CWD, offers the greatest opportunity for functional improvement. Thus, greater involvement of the individuals who surround the CWD offers a greater potential for success. Pediatric rehabilitation approaches that provide detailed education about home exercise programs, behaviour management and feedback about parents' techniques will increase confidence and adherence and will reinforce the impact of rehabilitation on the child's functional status. More broadly, rehabilitation providers can also respond to these findings by linking parents with other services that may help in the management of daily life (e.g., support groups, play groups, respite services). If these services are lacking, therapists are in an ideal position to advocate for additional supportive services for their patients.

\section{Conclusions}

This study contributes valuable information about the ways in which Kuwaiti mothers perceive disability, their children, their communities and rehabilitation services. This research reaffirms the role that religion plays in mothers' understanding of their child's condition and their ability to cope with extensive caregiving demands. For rehabilitation providers, understanding that the integration of religious beliefs with rehabilitation practices is possible will be an important part of expanding a 
family-centred approach to care delivery. Problematic community perceptions about disability are modifiable through education, as it is part of a rehabilitation provider's role to educate both family members and the larger community about the nature and abilities of CWD. Lastly, healthcare professionals can aid in the process of mainstreaming CWD and their families into the community, as the mothers noted that increased understanding of disability in the greater community would facilitate integration of their children.

\section{Acknowledgements}

The authors would like to acknowledge the participants who generously offered their time and opinions, and to the contribution of Ms. Shahad Aldhayea and Ms. Fatma Mohammed Alshatti who were part of the LOYAC program during the data collection phase of this study.

\section{References}

Armstrong, J. and A. Ager. 2005. "Perspectives on Disability in Afghanistan and Their Implications for Rehabilitation Services." International Journal of Rehabilitation Research 28(1): 87-92.

Balasundaram, P. 2007. "Love Is Not a Feeling: Faith and Disability in the Context of Poverty." Journal of Religion, Disability and Health 11(2): 15-22.

Brandon, P. 2007. “Time Away from 'Smelling the Roses': Where Do Mothers Raising Children with Disabilities Find the Time to Work?” Social Science \& Medicine 65: 667-9.

Brown, T., K. Mu, C.G. Peyton, S. Rodger, K. Stagnitti, E. Hutton, J. Casey, C. Watson, C.S. Hong, Y. Huang and C. Wu. 2000. "Occupational Therapy Students' Attitudes towards Individuals with Disabilities: A Comparison between Australia, Taiwan, the United Kingdom, and the United States." Research in Developmental Disabilities 30(6): 1541-55.

Burker, E.J., D.M. Evon, J.A Sedway and T. Egan. 2005. "Religious and Non-Religious Coping in Lung Transplant Candidates: Does Adding God to the Picture Tell Us More?" Journal of Behavioural Medicine 28(6): 513-26.

Chang, M. and R. McConkey. 2008. "The Perceptions and Experiences of Taiwanese Parents Who Have Children with an Intellectual Disability." International Journal of Disability, Development and Education 55(1): 27-41.

Cieza, A., R. Hilfiker, S. Chatterji, N. Kostanjsek, B.T. Üstün and G. Stucki. 2009. "The International Classification of Functioning, Disability, and Health Could Be Used to Measure Functioning." Journal of Clinical Epidemiology 62(9): 899-911.

Crabtree, A.S. 2007. "Family Responses to the Social Inclusion of Children with Developmental Disabilities in the United Arab Emirates." Disability \& Society 22(1): 49-62.

Croot, E.J., G. Grant, C.L. Cooper and N. Mathers. 2008. "Perceptions of the Causes of Childhood Disability among Pakistani Families Living in the UK." Health and Social Care in the Community 16(6): 606-13.

Danesco, E.R. 1997. "Parental Beliefs on Childhood Disability: Insights on Culture, Child Development and Intervention.” International Journal of Disability, Development and Education 44(1): 41-52.

Daudji, A., S. Eby, C. Foo, F. Ladak, C. Sinclair, K. Moodie, M.D. Landry and B. Gibson. (in press). "Exploring Perceptions of Disability among Immigrant Mothers of Children with Disabilities (CWD).” Disability \& Rehabilitation

Diken, I.H. 2006. “Turkish Mothers' Interpretation of the Disability of Their Children with Mental Retardation.” International Journal of Special Education 21(2): 8-17.

Gan, C., K.A. Campbell, A. Snider, S. Cohen and J. Hubbard. 2008. "Giving Youth a Voice (GYV): A Measure of Youths' Perceptions of the Client-Centredness of Rehabilitation Services.” Canadian Journal of Occupational Therapy 75(2): 96-104.

Gething, L. 1992. "Nurse Practitioners' and Students' Attitudes towards People with Disabilities." Australian Journal of Advanced Nursing 9(3): 25-30.

Green, S.E. 2003. “'What Do You Mean "What's Wrong with Her?”: Stigma and the Lives of Families of Children with Disabilities.” Social Science \& Medicine 57(8): 1361-75.

Hosain, G.M, M.M. Hosain, K.C. Ganguly, N. Chatterjee and D. Atkinson. 2005. "Use of Unqualified Practitioners by Disabled People in Rural Bangladesh.” Mymensingh Medical Journal 14(2): 160-4.

Huang, Y., J.H. Fried and T. Hsu. 2009. “Taiwanese Mothers' Attitude Change towards Individuals with Disabilities." Journal of Social Work in Disability \& Rehabilitation 8(2): 82-94. 
Kerem Günel, M. 2009. "Rehabilitation of Children with Cerebral Palsy from a Physiotherapist's Perspective." Acta Orthopaedica et Traumatologica Turcica 43(2): 173-80.

Khamis, V. 2007. "Psychological Distress among Parents of Children with Mental Retardation in the United Arab Emirates." Social Science \& Medicine 64(4): 850-7.

King, S., R. Teplicky, G. King and P. Rosenbaum. 2004. "Family-Centered Service for Children with Cerebral Palsy and Their Families: A Review of the Literature.” Seminars in Pediatric Neurology 11(1): 78-86.

Law, M., S. Hanna, G. King, P. Hurley, S. King, M. Kertoy and P. Rosenbaum. 2003. "Factors Affecting FamilyCentred Service Delivery for Children with Disabilities." Child Care Health Development 29(5): 357-66.

Maloni, P., J. Habbous, A. Primmer, B. Despres, J. Slatten, S. Nixon, B. Gibson and M.D. Landry. 2010. "Exploring the Perceptions of Disability among Mothers of Children with Disabilities (CWD) in Bangladesh." Disability and Rehabilitation 32(10): 845-54.

Masala, C. and D.R. Petretto. 2008. "Conceptual Models of Disability in the 20th Century." Disability and Rehabilitation 30(17): 1233-44.

Miller, M.J. 1996. "Attitudes of Service Students towards Persons with Disabilities.” Doctoral Dissertation. University of Maine.

Pope, C., S. Ziebland and N. Mays. 2000. "Qualitative Research in Health Care: Analyzing Qualitative Data." British Medical Journal 320: 114-6.

Rauch, A., I. Kirchberger, C. Boldt, A. Cieza and G. Stucki. 2009. "Does the Comprehensive International Classification of Functioning, Disability and Health (ICF) Core Set for Rheumatoid Arthritis Capture Nursing Practice? A Delphi Survey." International Journal of Nursing Studies 46(10): 1320-34.

Rippentrop, A.E, E.M. Altmaier, J.J. Chen, E.M. Found and V.J. Keffala. 2005. "The Relationship between Religion/Spirituality and Physical Health, Mental Health, and Pain in a Chronic Pain Population.” Pain 116(3): 311-32.

Sen, E. and S. Yurtsever. 2007. “Difficulties Experienced by Families with Disabled Children.” Journal for Specialists in Pediatric Nursing 12(4): 238-52.

Treloar, L.L. 2002. "Disability, Spiritual Beliefs and the Church: The Experiences of Adults with Disabilities and Family Members." Journal of Advanced Nursing 40(5): 594-603.

Wahl, H.-W., A. Fänge, F. Oswald, L.N. Gitlin and S. Iwarsson. 2009. "The Home Environment and DisabilityRelated Outcomes in Aging Individuals: What Is the Empirical Evidence?” Gerontologist 49(3): 355-67.

Wiart, L. and J. Darrah. 2002. "Changing Philosophical Perspectives on the Management of Children with Physical Disabilities - Their Effect on the Use of Powered Mobility." Disability and Rehabilitation 24(9): 492-8.

World Health Organization. 1980. "International Classification of Impairments, Disabilities and Handicaps: A Manual of Classification Relating to the Consequences of Diseases." Geneva: WHO.

World Health Organization. 2001. "International Classification of Functioning, Disability and Health." Geneva: WHO.

World Health Organization. 2008. “World Report on Disability and Rehabilitation.” Retrieved May 11, 2010 <http://www.who.int/disabilities/Concept\%20NOTE\%20General\%202008.pdf>.

Wynia, K., B. Middel, H. De Ruiter, J.P. Van Dijk, W.S. Lok, J.H. De Keyser and S.A. Reijneveld. 2009. “Adding a Subjective Dimension to an ICF-Based Disability Measure for People with Multiple Sclerosis: Development and Use of a Measure for Perception of Disabilities." Disability and Rehabilitation 31(12): 1008-17.

Yousef, J. 1994. "Handicapped People in Jordan: The Present Situation." International Child Welfare Review 62(1): 22-8. 


\section{Appendix: Interview Guide}

\section{Section 1: Personal/Background Information}

1.1 What is your country of birth?

1.2 How many children do you have?

1.3 Do you have any other children with disabilities?

1.4 How often do you attend rehabilitation with your child?

\section{Section 2: Perception of Disability}

2.1 How did you find out about your child's disability?

2.2 When did you find out that your child had a disability? Who informed you?

2.3 Do you know the name of the medical term of what disability your child has?

2.4 How did you feel when you found out that your child had a disability?

2.5 How has your role changed since (child's name) has come into your life?

2.6 How does religion impact how you feel about your child's disability?

2.7 What do you believe caused the disability in your child?

2.8 What does disability mean to you?

2.9 How does your community view disability?

2.10 How does your community view your child's disability?

2.11 How does the rest of you family view your child's disability?

2.12 Do you have support from your family or the community?

\section{Section 3: Rehabilitation Services}

3.1 What made you decide to pursue rehabilitation treatment for your child?

3.2 How did you hear about the [name of hospital]?

3.3 How do you feel about the services here [name of hospital]?

3.4 What are other treatments (medical/non-medical) have you used to treat your child? 